\title{
Trening sportowy jako czynnik wpływający na przebieg wzrastania organizmu - badania wyczynowych łyżwiarek figurowych
}

\section{The role of intense physical activity in the formation of body shape - research based on female figure skaters}

\author{
Monika Paluchowska \\ Zakład Antropologii Instytutu Zoologii Uniwersytetu Jagiellońskiego \\ ul. Gronostajowa 9, 30-387 Kraków \\ Kierownik: dr hab. Henryk Gtąb \\ Klinika Pediatrii i Endokrynologii Warszawskiego Uniwersytetu Medycznego \\ ul. Żwirki i Wigury 63A, 02-091 Warszawa \\ Kierownik: dr hab. n. med. Beata Pyrżak
}

\section{SUMMARY}

Introduction: The article concerns figure skating competitors. Figure skating is a very demanding discipline. It requires a combination of endurance, strength and flexibility. The training ground is ice, which puts strain on the muscles and skeleton. Young children often train more than is healthy for a young and growing body. The aim of the study was to determine the effect of training on the height and weight of female skaters.

Material and methods: 181 measurements were taken from three skating clubs, and a survey was conducted among skaters' parents about skaters' siblings.
Results: Female skaters are relatively shorter and lighter than their peers, but the differences were not statistically significant. Significant differences were noted between girls whose sisters do not do sports.

Conclusion: The results suggest the influence of genetic factors and selection processes on the morphology of the skaters' body.

Key words: biological development, body height, sports training, figure skating.

\section{STRESZCZENIE}

Wstęp: Łyżwiarstwo figurowe jest bardzo wymagającą dyscypliną sportu, kombinacją wytrzymałości, siły oraz gibkości. Podłożem treningowym jest lodowa tafla, co dodatkowo obciąża układ ruchu. Wysoki poziom dyscypliny sprawia, że coraz młodsi zawodnicy trenują w liczbie godzin wykraczającej poza normy uznane za bezpieczne dla młodego, wzrastającego organizmu.

Celem pracy była ocena rozwoju biologicznego dziewczynek uprawiających łyżwiarstwo figurowe na podstawie analizy danych uzyskanych z pomiarów zawodniczek polskich klubów sportowych. Porównano także przebieg rozwoju młodych łyżwiarek do ich sióstr nieuprawiających tej dyscypliny sportu.
Materiał i metody: Zebrano 181 pomiarów dziewcząt z 3 klubów łyżwiarskich oraz przeprowadzono ankiety wśród ich rodziców na temat rodzeństwa łyżwiarek.

Wyniki: Zawodniczki są stosunkowo niższe i lżejsze od swoich rówieśniczek, jednak różnica ta nie jest istotna statystycznie. Odnotowano natomiast znaczne rozbieżności między dziewczynkami a ich siostrami, które nie trenowały żadnej dyscypliny sportowej.

Wnioski: Wyniki pozwoliły również wnioskować o wpływie czynników genetycznych oraz selekcji na morfologię zawodniczek łyżwiarstwa figurowego.

Słowa kluczowe: rozwój biologiczny, wysokość ciała, aktywność fizyczna, łyżwiarstwo figurowe.

\section{WSTĘP}

W Polsce coraz bardziej popularnym sportem staje się łyżwiarstwo figurowe, które można uprawiać zarówno w formie rekreacyjnej, jak i wyczynowej. Według Banku Danych Lokalnych liczba osób trenujących tę dyscyplinę sportu w Polsce systematycznie się powiększa. Z ok. 400 osób trenujących w 1999 r. liczba ta wzrosła do ponad 1100 w 2010 r. [1]. Łyżwiarstwo figurowe jest sportem będącym kombinacją wytrzymałości, siły, gibkości i gracji z nutą artystyczną, wykonywanym na nienaturalnym podłożu, jakim jest lodowa tafla. Wysoki poziom dyscypliny zmusza coraz młodszych zawodników do treningów wykraczających poza normy uznane za bezpieczne dla młodego, wzrastającego organizmu [2]. Kariera zawodnika najczęściej zaczyna się w wieku 5-6 lat i kończy jeszcze na etapie szkolnym. Nieliczni osiągają wiek seniorski, a jeszcze mniejsza liczba startuje w zawodach po osiągnięciu 20. r.ż. Trening łyżwiarza figurowego jest bardzo wszechstronny. Składa się nie tylko z zajęć na lodzie obejmujących doskonalenie elementów jazdy na łyżwach, ale również różnorodnych zajęć poza [3], które polegają na zwiększaniu siły, wytrzymałości i gibkości poprzez ćwiczenia ogólnorozwojowe, aerobowe oraz statyczne. 
TABELA 1. Program szkoleniowy (obciążenie treningowe w min/tydzień)

\begin{tabular}{|c|c|c|c|c|c|c|c|}
\hline Wiek & Lód & Balet & Akrobatyka & $\begin{array}{l}\text { Trening } \\
\text { imitacyjny }\end{array}$ & $\begin{array}{c}\text { Trening } \\
\text { wszechstronny }\end{array}$ & Basen & $\begin{array}{c}\text { Odnowa } \\
\text { biologiczna }\end{array}$ \\
\hline $4-5$ & $2 \times 45 \mathrm{~min}$ & $1 \times 45 \mathrm{~min}$ & - & - & - & $1 \times 45 \mathrm{~min}$ & - \\
\hline $6-7$ & $4 \times 45 \mathrm{~min}$ & $2 \times 45 \mathrm{~min}$ & - & - & $1 \times 45 \mathrm{~min}$ & $1 \times 45 \mathrm{~min}$ & - \\
\hline $7-8$ & $6 \times 60 \mathrm{~min}$ & $2 \times 45 \mathrm{~min}$ & $1 \times 45 \mathrm{~min}$ & $1 \times 45 \mathrm{~min}$ & $2 \times 45 \mathrm{~min}$ & $1 \times 45 \mathrm{~min}$ & $1 x$ \\
\hline $9-10$ & $6 \times 60 \mathrm{~min}$ & $2 \times 60 \mathrm{~min}$ & $1 \times 75 \mathrm{~min}$ & $1 \times 60 \mathrm{~min}$ & $2 \times 60 \mathrm{~min}$ & $1 \times 45 \mathrm{~min}$ & $1 \times$ \\
\hline $11-12$ & $6 \times 120 \mathrm{~min}$ & $2 \times 60 \mathrm{~min}$ & $1 \times 75 \mathrm{~min}$ & $1 \times 60 \mathrm{~min}$ & $2 \times 60 \mathrm{~min}$ & $1 \times 45 \mathrm{~min}$ & $2 \times$ \\
\hline $13-14$ & $6 \times 150 \mathrm{~min}$ & $2 \times 60 \mathrm{~min}$ & $1 \times 75 \mathrm{~min}$ & $1 \times 60 \mathrm{~min}$ & $3 \times 60 \mathrm{~min}$ & $1 \times 45 \mathrm{~min}$ & $2 \times$ \\
\hline $15-16$ & $6 \times 180 \mathrm{~min}$ & $2 \times 60 \mathrm{~min}$ & $1 \times 90 \mathrm{~min}$ & $1 \times 60 \mathrm{~min}$ & $3 \times 60 \mathrm{~min}$ & $1 \times 45 \mathrm{~min}$ & $2 \times$ \\
\hline $17-18$ & $6 \times 180 \mathrm{~min}$ & $2 \times 60 \mathrm{~min}$ & $1 \times 90 \mathrm{~min}$ & $1 \times 60 \mathrm{~min}$ & $3 \times 60 \mathrm{~min}$ & $1 \times 45 \mathrm{~min}$ & $2 \times$ \\
\hline $19<$ & $6 \times 210 \mathrm{~min}$ & $2 \times 60 \mathrm{~min}$ & $1 \times 90 \mathrm{~min}$ & $1 \times 60 \mathrm{~min}$ & $3 \times 60 \mathrm{~min}$ & $1 \times 45 \mathrm{~min}$ & $2 x$ \\
\hline
\end{tabular}

Są one równie ważne jak praca na lodzie, chociażby dlatego, że elementy skoków wymagają połączenia siły, szybkości oraz koordynacji ruchowej. Zawodnicy korzystają też z zajęć tanecznych i akrobatycznych [4]. Zalecaną liczbę godzin treningowych w zależności od wieku zamieszczono w tabeli 1 [4]

Program ten zakłada, że 11-12-letnie dziecko spędza na treningu średnio 19 godz. tygodniowo, ale zdarza się, że dobrze rokujący zawodnicy trenują znacznie więcej. Tak duża ilość intensywnego treningu znacznie częściej niż zajęcia rekreacyjne powoduje niekorzystne zmiany w fizjologii organizmu młodego łyżwiarza figurowego oraz wpływa na ekosensytywne cechy masy i wysokości ciała. Zdarza się także, że bywa przyczyną wad rozwojowych. Typowe problemy zdrowotne wśród łyżwiarzy figurowych obejmują bóle mięśniowo-szkieletowe, urazy w obrębie stóp, kostek, kolan, bioder oraz dolnej części pleców. Łyżwiarze są też bardziej niż przeciętne osoby narażeni na skurcze oskrzeli wywołane nadmiernym wysiłkiem fizycznym oraz na zaburzenia odżywiania. Te ostatnie częściej obserwuje się wśród łyżwiarek niż łyżwiarzy i są one głównie powodowane przekonaniem o lepszej przydatności do sportu lżejszych i niższych osób [5, 6].

Długotrwały trening sportowy może u dziewczynek także opóźniać menarche, co przez wielu trenerów jest postrzegane jako korzystne w kwestii utrzymania odpowiedniej formy. Podczas dojrzewania płciowego następuje szybki przyrost tkanki tłuszczowej, która zwiększa masę ciała i utrudnia wykonywanie skoków. Trudności z rotacją mogą być również spowodowane poszerzeniem się bioder oraz zmianą środka ciężkości i osłabieniem koordynacji ruchowej. Wielu zawodniczkom osiągającym sukcesy w wieku dziecięcym nie udaje się ich powtórzyć po okresie dojrzewania płciowego [7, 8].

Celem pracy była ocena rozwoju biologicznego dziewczynek uprawiających łyżwiarstwo figurowe na podstawie analizy danych uzyskanych z pomiarów zawodniczek polskich klubów sportowych. Porównano także przebieg rozwoju młodych łyżwiarek do ich sióstr, nieuprawiających tej dyscypliny sportu.

\section{MATERIAtY I METODY}

Pomiary wysokości i masy ciała zostały zebrane od dzieci trenujących wyczynowo łyżwiarstwo figurowe w 3 polskich klubach sportowych. Zebrane informacje zawierały także dane na temat daty urodzenia oraz wieku rozpoczęcia treningów. Bazę stanowiło 181 pomiarów zawodniczek trenujących łyżwiarstwo figurowe. Najmłodsza zawodniczka w chwili pomiaru miała 5 lat i 5 miesięcy, a najstarsza 24 lata i miesiąc (tab 2). Najliczniejszą grupę stanowiły 9-latki (43 pomiary). Dodatkowym narzędziem były ankiety przeprowadzone wśród rodziców zawodników dotyczące morfologii ciała rodzeństwa badanych dziewczynek. Informacje te, to: wiek, wysokość i masa ciała oraz aktywność sportowa. Zawodniczki podzielono na klasy wiekowe zgodnie z regułą: 6-latki to dzieci w granicy 5,50-6,49, 7-latki w przedziale 6,50-7,49 itd. Osoby powyżej 18. r.ż. zakwalifikowano do grupy 18-latków. Następnie ze względu na małą liczbę danych w kilku klasach wiekowych dane unormowano w oparciu o wartości średnich wysokości ciała dziewcząt polskich, opracowaną w projekcie „Olaf” (2007-2009) [9] według wzoru:

$$
\text { Z-scores }=\frac{\mathrm{X}-\mathrm{X}_{\text {Srednia }}}{\mathrm{S}}
$$

TABELA 2. Liczba zmierzonych zawodniczek w poszczególnych klasach wiekowych

\begin{tabular}{lccccccccccccc}
\hline $\begin{array}{l}\text { Klasa } \\
\text { wiekowa }\end{array}$ & 6 & 7 & 8 & 9 & 10 & 11 & 12 & 13 & 14 & 15 & 16 & 17 & 18 \\
\hline $\mathrm{n}$ & 4 & 15 & 29 & 43 & 22 & 28 & 14 & 10 & 9 & 4 & 2 & 0 & 1
\end{tabular}

Istotność różnic pomiędzy dwoma średnimi sprawdzano przy użyciu testu t Studenta. Porównując 3 grupy, stosowano jednoczynnikową analizę wariancji. Za poziom istotności przyjęto $\mathrm{p}<0,05$

\section{WYNIKI}

Porównywano wyniki wysokości ciała oraz wskaźnik masy ciała (BMI) łyżwiarek figurowych do średniej populacji. Sprawdzono również, jak zmienia się odchylenie od średniej wraz z wiekiem zawodniczek, dzieląc je na grupy wiekowe przed okresem dojrzewania (6-9 lat), w jego trakcie (10-14 lat) i po nim (15-18 lat). Łyżwiarki figurowe okazały się być niższe od swoich rówieśniczek, jednak różnica ta nie przekraczała 0,5 SD (tab. 3). Przy podziale na grupy wiekowe różnica 
od średniej populacji dziewcząt polskich wzrasta wraz z wiekiem łyżwiarek. W pierwszej grupie (przed okresem dojrzewania) wynosi tylko -0,29 SD, w drugiej (w czasie okresu dojrzewania) -0,50 SD, a w ostatniej (po okresie dojrzewania płciowego) już -0,79 SD. Różnice te nie są istotne statystycznie, jednak ukazują tendencję wzrostowe (ryc. 1). Dane dla młodych łyżwiarek figurowych zestawiono również z danymi od ich nietrenujących sióstr. W przypadku porównania zawodniczek do ich sióstr, które jak wynikało z przeprowadzonych ankiet, nie były aktywne sportowo, łyżwiarki były niższe (tab. 4, ryc. 2). Różnica ta okazała się być istotna statystycznie (test t Studenta: $t=-3,06, p=0,0064$ ), co sugeruje większy wpływ czynnika treningu sportowego na wzrost niż czynników genetycznych.

Wartość wskaźnika masy ciała obliczono z wzoru BMI = masa (kg) / wysokość ${ }^{2}$ (m). Adekwatnie jak w przypadku wysokości ciała dane unormowano. Średnia wartość wyniosła-0,43, czyli nieco więcej niż w przypadku wysokości, jednak ciągle nie przekraczała 0,5 SD (tab. 5). Po podziale na grupy wiekowe zanotowano zbliżone wartości w dwóch pierwszych klasach 6-9 oraz 10-14. Dziewczynki te są lżejsze od swoich rówieśniczek. W obrębie zawodniczek najstarszych średnia wartości BMI jest najwyższa i bardzo zbliżona do średniej populacyjnej. Oznacza to, że wraz z wiekiem stosunek masy ciała do jego wysokości wśród łyżwiarek figurowych rośnie (ryc. 3). Różnice między przedziałami wiekowymi są jednak nieistotne statystycznie: $F=2,71$, a $p=0,07$. Porównując dziewczynki trenujące wyczynowo do ich sióstr deklarujących małą aktywność fizyczną, lżejsze okazały się łyżwiarki. Różnica między BMI zawodniczej a ich rodzeństwa jest statystycznie istotna, $\mathrm{t}=-5,23 \mathrm{i} \mathrm{p}=0,0001$ (tab. 6, ryc. 4). Świadczy to o dodatnim wpływie aktywności fizycznej na masę ciała.
TABELA 3. Wartości unormowane wysokości ciała zawodniczek

\begin{tabular}{cccccc}
$\mathbf{n}$ & $\overline{\mathbf{x}}$ & Mediana & $\mathbf{s}$ & Minimum & Maksimum \\
\hline 181 & $-0,41$ & $-0,51$ & 0,88 & $-2,46$ & 2,20 \\
\hline
\end{tabular}

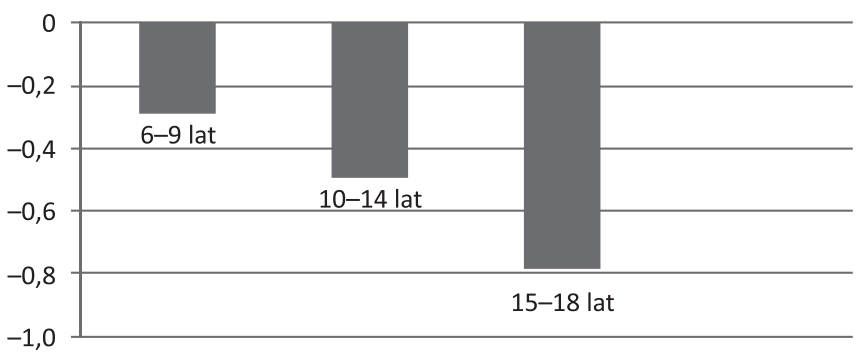

RYCINA 1. Wartości unormowane wysokości ciała zawodniczek w poszczególnych przedziałach wiekowych

TABELA 4. Wartości unormowane wysokości ciała zawodniczek oraz ich nietrenujących sióstr

\begin{tabular}{lcccccc}
$\begin{array}{c}\text { Osoba } \\
\text { badana }\end{array}$ & $\mathbf{n}$ & $\overline{\mathbf{x}}$ & Mediana & $\mathbf{s}$ & Minimum & Maksimum \\
\hline Zawodniczka & 10 & $-1,15$ & $-1,05$ & 0,58 & $-2,46$ & $-0,39$ \\
\hline $\begin{array}{l}\text { Siostra } \\
\text { nietrenująca }\end{array}$ & 10 & 0,20 & 0,27 & 1,26 & $-2,15$ & 1,93 \\
\hline
\end{tabular}

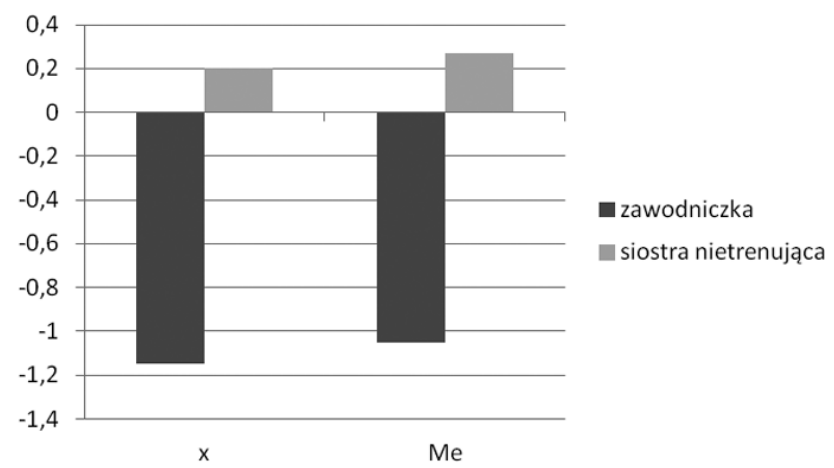

RYCINA 2. Wartości unormowane wysokości ciała zawodniczek oraz ich nietrenujących sióstr
TABELA 5. Wartości unormowane BMI u badanych zawodniczek

\begin{tabular}{cccccc}
$\mathbf{N}$ & $\overline{\mathbf{x}}$ & Mediana & $\mathbf{S}$ & Minimum & Maksimum \\
\hline 180 & $-0,43$ & $-0,50$ & 0,57 & $-1,55$ & 1,04 \\
\hline
\end{tabular}

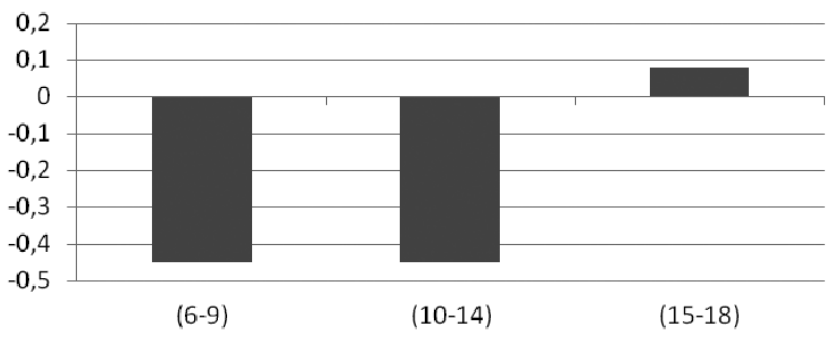

RYCINA 3. Wartości unormowane BMI u badanych zawodniczek, w poszczególnych klasach wiekowych

TABELA 6. Wartości unormowane BMI badanych zawodniczek $i$ ich nietrenujących sióstr

\begin{tabular}{lcccccc}
$\begin{array}{c}\text { Osoba } \\
\text { badana }\end{array}$ & $\mathbf{n}$ & $\overline{\mathbf{x}}$ & Mediana & $\mathbf{s}$ & Minimum & Maksimum \\
\hline Zawodniczka & 10 & $-0,55$ & $-0,56$ & 0,57 & $-1,40$ & 0,52 \\
\hline $\begin{array}{l}\text { Siostra } \\
\text { nietrenująca }\end{array}$ & 10 & 0,78 & 0,83 & 0,56 & $-0,06$ & 1,71 \\
\hline
\end{tabular}

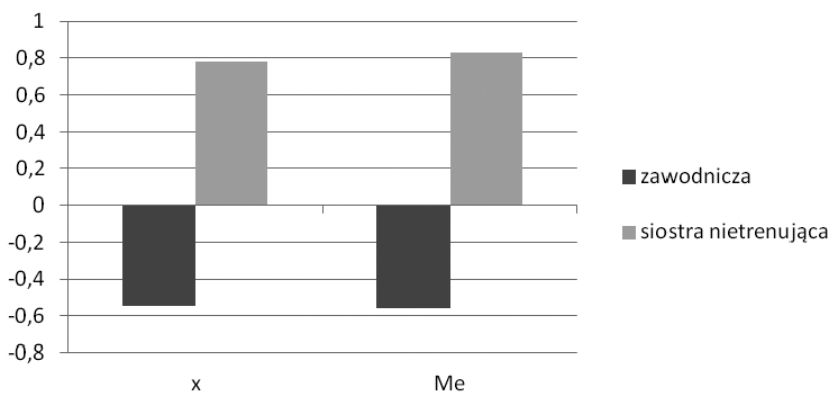

RYCINA 4. Wartości unormowanych BMI badanych zawodniczek i ich nietrenujących sióstr 


\section{DYSKUSJA}

Liczne międzynarodowe badania prowadzone wśród łyżwiarek figurowych wskazują, że przeciętna wysokość ich ciała plasuje się poniżej 50. centyla względem wieku [2]. Niniejsza próba zdaje się potwierdzać tę hipotezę, choć można również znaleźć publikacje będące w sprzeczności z tym twierdzeniem $[10,11,12]$. Fakt, że różnica w odchyleniu wysokości ciała od średniej populacji zwiększa się wraz z wiekiem zawodniczek, najlepiej zdaje się potwierdzać wpływ treningu na ten parametr morfologii ciała. Potwierdza to również znacząca różnica w średniej wysokości ciała między rodzeństwem, z których jedno uprawia łyżwiarstwo figurowe, a drugie pozostaje bierne sportowo.

Obciążenie treningowe ma duże znaczenie w kształtowaniu się kośćca, co może mieć konsekwencje w powstawaniu patologii, ale również w obniżaniu szybkości wzrostu kości długich. Przyczyną może być intensywniejszy przyrost tych kości na grubość, kosztem długości. Siły działające na kości kończyn dolnych oddziałują również na kręgosłup, mogąc zmniejszać przestrzenie między kręgami [13, 14, 15]. Wszystko to może mieć odzwierciedlenie w wysokości ciała zawodników długotrwale uprawiających łyżwiarstwo figurowe. Nie bez znaczenia jest również fakt, że intensywny trening sportowy opóźnia wystąpienie menarche i tzw. skoku pokwitaniowego, a w pojedynczych przypadkach może prowadzić nawet do zahamowania wzrostu [16]. Wszystkie te czynniki mogą mieć wpływ na tendencje łyżwiarek figurowych do wysokości ciała niższej niż przeciętna. W rozważaniach nie można jednak pominąć selekcji, która faworyzuje osoby o bardziej leptosomicznej morfologii, co może się przyczyniać do dłuższego pozostawania w tej dyscyplinie sportu osób z uwarunkowaną genetycznie niższą wysokością ciała.

Wskaźnik masy ciała jest nieznacznie niższy u łyżwiarek figurowych niż przeciętnych dziewczynek. Przed okresem dojrzewania, jak i w jego trakcie różnica ta zaznacza się wyraźniej. Po tym okresie stosunek masy do wysokości ciała znacznie zbliża się do średniej, a nawet lekko ją przewyższa. Niższa wartość BMI, tak samo jak wysokość ciała, jest preferowana w dyscyplinie łyżwiarstwa figurowego. Im zawodnik ma niższą masę, tym mniej energii musi włożyć w wykonanie niektórych elementów (np. skoki). Zawodnicy z takimi parametrami odznaczają się również lepszą koordynacją ruchową [4, 17]. W gorszej pozycji w porównaniu do chłopców są dziewczynki, dlatego że w morfologii ich ciała dojrzewanie płciowe zaznacza się zdecydowanie silniej.

Jednym z elementów skoku pokwitaniowego u dziewcząt jest znaczny przyrost tkanki tłuszczowej, a intensywny trening sprzyja równiej wzrostowi masy mięśniowej [15, 16]. Może to wyjaśniać, dlaczego w ostatniej grupie wiekowej (po okresie dojrzewania) wartość BMI zbliżyła się do wartości średniej dla populacji. Wiadomo natomiast, że lepsze wyniki w sporcie, jakim jest łyżwiarstwo figurowe, mają zawodnicy ze stosunkowo niską masą i wysokością ciała. Zapewne dlatego szczyt formy zawodniczek tej dyscypliny najczęściej przypada na wiek przed osiągnięciem dojrzałości płciowej, a tylko nieliczne dziewczęta mają podobne osiągnięcia w późniejszym czasie. Oznacza to, że zawodniczki późno dojrzewające mają większe szanse na osiągnięcie sukcesu sportowego $[16,18]$.

\section{WNIOSKI}

1. Trening wyczynowego łyżwiarza figurowego wywiera wpływ na jego kondycję biologiczną oraz morfologię ciała.

2. Łyżwiarki figurowe są przeciętnie niższe od swoich rówieśniczek, jednak różnica nie przekracza 0,5 SD. Różnica wysokości ciała łyżwiarek w stosunku do średniej populacji dziewcząt polskich wzrasta wraz z wiekiem.

3. W porównaniu do swoich nieaktywnych sportowo sióstr zawodniczki są istotnie niższe, co sugeruje większy wpływ czynnika treningu sportowego na wzrost niż czynników genetycznych.

4. Wskaźnik masy ciała łyżwiarek figurowych jest stosunkowo niższy od przeciętnej i przyjmuje wartość zbliżoną do 0,5 SD.

5. Zawodniczki po okresie dojrzewania charakteryzują się BMI bardzo zbliżonym do średniej populacyjnej dziewcząt polskich, co zapewne ma związek ze zmianą morfologii spowodowaną dojrzewaniem płciowym.

6. Łyżwiarki figurowe mają niższe BMI od swoich sióstr nieuprawiających sportu, co potwierdza wpływ treningu na masę ciała.

\section{PIŚMIENNICTWO}

1. Główny Urząd Statystyczny - Bank Danych Lokalnych, http://www.stat. gov.pl/bdl/app/strona.html?p_name=indeks (26.04.2013 r.).

2. Porter E., Young C., Niedfeldt M., Gottschlich L.: Sport-specific injuries and medician problems of figure skaters. Wis Med J. 2007, 106 (6), 330-334.

3. Mydlarz-Chruścińska I.: Wieloletni program szkolenia sportowego w łyżwiarstwie figurowym uwzględniający etapowość szkolenia oraz wiek adeptów w tej dyscyplinie sportu oparty na szkoleniu zawodników uczniów szkół sportowych. Polski Związek Łyżwiarstwa Figurowego, Oświęcim 2003.

4. Podolsky A., Kaufman K., Cahalan T., Aleshinskyi S., Chao E.: The relationship of strength and jump height on figure skaters. Am j Sports Med.1990, 18 (4), 400-405.

5. Fortin J., Roberts D.: Competitive figure skating injuries. Pain Physician. 2003, 6 (3), 313-318.

6. Ziegler P., Hensley S., Roepke J., Whitaker S., Craig B., Drewnowski A.: Eating attitudes and energy intakes of famale skaters. Med Sci Sports Exerc. 1998, 30 (4), 583-586.

7. Malinowski A.: Auksologia. RWUZ, Zielona Góra 2004.

8. Wolański N.: Rozwój biologiczny człowieka. PWN, Warszawa 2005.

9. Kułaga Z., Rożdżyńska A., Palczewska I., Grajda A., Gurzkowska B., Napieralska E. et al.: Siatki centylowe wysokości, masy ciała i wskaźniki masy ciała dzieci i młodzieży w Polsce, wyniki badania OLAF. MEN, Warszawa 2011.

10. Ziegler P., Sharp R., Hughes V., Evans W., San Khoo C.: Nutritional status of teenage female competitive figure skaters. J Am Diet Assoc. 2002, 102 (3), 374-379.

11. Ziegler P., Nelson J., Barratt-Fornell A., Fiveash L., Drewnowski A.: Energy and macronutrient intakes of elite figure skaters. J Am Diet Assoc. 2001, 101 (3), 319-325. 
12. Ziegler P., San Khoo C., Sherr B., Nelson J., Larson W., Drewnowski A.: Body image and dieting behaviors among elite figure skaters. Int J Ear Disord. 1998, 24 (4), 421-427.

13. Oleson C., Busconi B., Baran D.: Bone density in competitive figure skaters. Arch Phys Med Rehabil. 2002, 83 (1), 122-128.

14. Dziewulski M.: Zagrożenia zdrowotne u młodzieży uprawiającej sport. Med Rodz. 2004, 3, 105-108.
15. Drozdowski Z.: Antropologia sportowa, morfologiczne podstawy wychowania fizycznego i sportu. PWN. Poznań 1984.

16. Łaska-Mierzejewska T.: Antropologia w sporcie i wychowaniu fizycznym. COS, Warszawa 1999

17. Lipetz J., Kruse R.: Injuries and special concerns of female figure skaters. Clin Sports Med. 2000,19 (2)

18. Smith A.: The young skater. Clin Sports Med. 2000, 19 (4), 741-755 